\title{
推进科学前瞻 迎接未来挑战
}

\section{中国科学院 路甬祥}

党中央在总结人类经济社会发展、特别是中国特色 社会主义发展的经验教训和吸取了全人类文明进程的 科学积累基础上, 提出了科学发展观. 随着经济社会的 发展和人类文明的进步, 人类终将走向经济社会的协调 发展、人与自然的和谐相处、区域协调发展的道路, 科 学发展观是人类文明发展道路的必然选择.

为了落实科学发展观, 推进我国的经济社会真正 走向科学发展道路, 科技界必须提供科学的认知, 提高 人们对客观规律的认知和遵循能力; 提供技术支撑, 提 高我国的产业竞争力和经济发展质量; 提供科学规划、 咨询、决策的理论和方法, 提高国家和地区的民主科学、 决策的水平. 此外, 应组织科技专家和管理专家开展前 瞻性的科技战略研究，把握世界科技发展的趋势，凝聚 和部署我国科技未来发展的重点, 这也是国家经济社会 和科学技术发展的需要, 是贯彻落实科学发展观的需要, 是应对未来挑战和持续发展的需要.

在过去的 30 年, 我国的改革开放之所以取得举世 瞩目的成就, 其中一个重要的原因在于我们的党能够不 断解放思想, 实事求是, 与时俱进, 不断前瞻, 不断创 新, 不断打破陈规, 不僵化, 不停滞, 开拓进取, 始终坚 定改革开放的决心, 坚定发展的信念, 不断创新发展的 观念和方式. 提高我国自主创新能力、建设创新型国家 更需要这种精神. 当今世界, 科学技术发展日新月异, 科技在经济社会发展和国家安全中的作用日益提升, 我 国实现社会主义现代化，提高我国的国际竞争力，更加 需要经济和社会发展依靠科学技术, 更加需要科学技术 面向经济建设和社会发展. 我国科学技术的发展要摆脱 跟踪模仿, 走自主创新之路, 就必须对未来世界科学技 术的发展走向有所科学前瞻, 否则, 在全球科技与经济 快速发展浪潮中, 就难以把握主动权, 就会处于被动 地位.

科学前瞻首先要把握国家未来经济社会发展对科 技的需求, 还要把握世界科技发展的趋势, 要把重点放 在关系到我国未来发展的瓶颈问题、战略方向和世界科 技有可能发生重大突破的领域. 科学前瞻要与我国未来 发展的大趋势结合起来, 要与世界政治、经济、社会、
军事变革的大趋势结合起来, 要与世界科技末来发展的 大趋势结合起来, 要采用当今世界先进的理论和方法, 要把握国情, 把握科技发展的规律, 要关注世界经济、 政治、社会、军事变革对科技发展的影响, 要用历史和 前瞻的眼光, 站得高, 望得远, 瞄得准.

\section{能源科技应受到高度的重视}

当今世界, 人口的增长, 发展中国家工业化现代化 进程的加快, 将使全球能源消费总量进一步增加, 过去 一年多来石油、煤炭价格的不断攀升, 警示了化石能源 紧缺对世界发展的制约, 尽管最近由于全球性经济危机 导致化石能源价格出现大幅度波动, 但化石能源逐渐稀 缺的态势不会改变, 当这场影响全球的经济危机之后, 石油、煤炭价格仍可能将在高价位上波动. 而且, 大量 化石能源的消费所排放的 $\mathrm{CO}_{2}$ 和污染物, 也成为全球大 气环境和温室效应的重要原因. 能源科技的前瞻研究, 不仅要研究如何高效清洁利用好煤炭资源, 如何开发和 高效利用好国内外两种油气资源, 如何发展更安全更先 进的核能, 如何加快开发利用可再生能源, 更要把握世 界能源生产与消耗的发展趋势, 把握世界能源科技发展 的态势. 可再生能源将酝酿新的技术突破, 并将为人类 能源需求作出重要贡献, 人类终将建立高效、经济、清 洁和可持续的能源体系. 构建这一体系需要解决一系列 关键的科技问题. 例如, 要探索突破高效、低成本的光 电转换材料、太阳能转换、存储介质等; 在生物质能利 用方面, 要解决高效光合作用能源植物的篮选和培育, 纤维素、木质素转化, 高效、低成本催化剂的制备等; 在 煤炭高效清洁利用方面, 要解决新型清洁煤燃烧技术中 的催化燃烧及反应控制、煤化工转化过程中的多联产定 向转化控制; 在核能利用方面, 要解决新型核电技术、 加速器驱动次临界技术、核废料处理技术和核聚变技术 及有关材料等; 在天然气水合物方面, 要解决好资源评 估、规模安全、开采技术以及对环境影响等科技问题. 为 了实现我国经济社会的科学发展, 必须建立符合我国发 展需要和资源特色的能源科技创新体系, 需要前瞻部署 能源科技的基础性、战略性、前瞻性和系统性研究与开 发, 把握能源发展和能源结构转型的机遇, 掌握先进能 
源关键科学问题、核心技术和先进设备研发制造和系统 集成能力, 尽快缩小与国外先进能源科技的差距, 进入 世界能源科技与能源产业的前列, 支撑我国经济社会持 续发展.

\section{农业科技关系我国的民生}

在我国经济社会发展大局中, 农业的基础地位不 能动摇, 随着人口的增长和人民物质生活水平的不断提 升, 对农业产品的需求将显著增长. 我国的土地资源、 水资源有限, 十几亿中国人的粮食问题, 只能主要依靠 自己解决. 用有限的自然资源满足全社会对农产品数 量、质量、安全和多样的需求, 不仅需要增加投入和相 应的制度建设, 更需要农业科技自主创新能力的不断提 高和农业科技的前瞻部署. 例如, 在优势品种培育方面, 要充分发掘和利用国内外丰富的基因资源, 开发基于基 因组信息的关键生物技术, 突破植物光合作用转化利用 效率和抗逆品种等; 要采用系统生物学、基因与蛋白质 组学、基因工程等多学科交叉融合研究与开发, 发展健 康、安全、抗病、可持续的畜禽及水产品种和种养殖方 式; 在资源节约型农业方面, 要研究开发土壤保育和水 肥高效利用技术, 开发缓释、智能型化肥，推进建立耕 地、水分、养分资源节约型农业; 在食品安全方面, 要 在动植物安全生产、重大病虫害预防与控制、食品营养 优化、生产与加工环境安全控制等领域，实现科技突破 和技术创新, 为我国食品供给提供科技的保障; 在精准 农业和农业信息化方面, 要通过科技创新与产业化, 实 现农业信息化、数字化、精准化和农业生产与加工的智 能化. 现代农业提供的不仅是动植物食物, 还要生产一 部分能源、药物以及其他工业原料, 未来人类生存发展 所需要的大量可再生材料可能要从农业而来. 而这一切 都需要前瞻性的研究与部署. 一些前瞻性的问题, 我们 重视得还不够, 如高科技、高值农业产品生产, 一些发 达国家已经开始在做. 中国经济发展到今天这一程度, 再过 20 年, 我国经济总量可能到世界第二位. 我们现在 如果不考虑, 不前瞻, 可能会失去机遇.

\section{生态环境关系着我国可持续发展}

由于我国人口众多, 大部分地区自然环境先天脆 弱, 加上经济发展快速且发展方式粗放, 致使我国生态 退化十分严重, 环境污染不断加剧, 环境健康问题日益 突出, 环境公共事件时有发生, 目前我国城市化和区域 发展中的一些不科学不和谐不协调现象, 加剧了人与自 然的矛盾. 对于生态环境问题, 我们不仅需要利用科学 技术和政策制度完善解决目前面临的问题, 而且需要前
瞻部署和研究, 寻找出解决未来可能出现的问题的技术 和途径. 我们不仅要研究生态环境自身变化的规律, 更 要着重研究人类活动与生态环境之间的相互作用. 我们 要前瞻部署研究全球气候变化及其生态学机理, 退化系 统的修复与生物多样性的保育; 城市化与环境质量, 研 究湖泊、湿地、流域、海岸带与人类生活生产密切相关 地理环境的地球物理、化学与生物过程; 研究环境污染 的控制与修复手段, 清洁生产与循环经济, 研究环境污 染与健康效应; 要研究减少温室气体排放的技术, 不只 是 $\mathrm{SO}_{2} 、 \mathrm{NO}_{x}$, 还要研究发展 $\mathrm{CO}_{2}$ 减排、捕捉、储存、 转化、利用的方法与手段, 认知和有效调控大气中的碳、 氮等循环平衡; 我们要前瞻部署研究全球气候变化导致 陆地冰雪消融对海平面抬升的影响, 对陆地生态环境尤 其是海岸带与河口三角洲地区的可能影响; 要大力发展 先进的生态环境监测与预警、预报技术, 构建先进的生 态与环境监测网络平台, 以及基于系统理论、跨学科研 究基础上的数据分析与共享网络, 对生态与环境数据进 行整合与系统模拟. 历史的经验和各国发展的历程都告 诉我们, 对于生态环境问题, 再也不能等问题发生了才 研究解决, 否则酿成的损失、治理的成本和难度都将会 极大地增加.

\section{保障人口健康是经济发展与社会进步的根本目标}

我国是人口大国, 控制人口增长、改善人口质量、 提高人口的健康安全保障, 是我国长期的国策, 加强人 口健康科技的自主创新与前瞻部署和研究, 是科技界义 不容辞的责任. 我国人口基数很大, 计划生育工作需要 长期坚持, 研究开发先进的人口控制技术和药物刻不容 缓; 随着我国人口平均寿命的提高和生活方式的改变, 全社会的病谱正在发生改变, 肿瘤、心脑血管疾病、代 谢性疾病等慢性病的危害呈持续上升的趋势, 亟待研发 慢性病的预防、诊断和治疗的新知识和新技术; 我国正 在迈向老龄化社会, 老年人的身心健康问题愈加引起全 社会的重视; 随着社会生活方式的改变, 人的心理健康 问题也越来越应该引起人们的重视, 需要基于认知科学 技术上的心理与精神保健的治疗方式; 防止新型流行病 的传播, 对于我们这样一个人口大国来说, 也是时刻不 能放松的工作, 针对我国人口众多, 人口密度的特点, 需要注意发挥传统和现代结合的优势, 发展健康科学与 防治技术, 发展科学的新型流行病监测、预防、控制、 诊断、治疗方法, 保护十几亿人民的健康; 我国在未来 很长一段时间, 都要重视低保人员和农村群众看病难、 看病贵的问题, 如何开发低成本预防、诊断、治疗技术, 
是我国必须面对的问题; 我国是世界上药物使用量最多 的国家, 然而我国医药工业的创新能力低, 97\%以上药 品是仿制国外的品种, 急需开发创新新药, 提高我国医 药产业的竞争能力, 而且要根据科技的发展, 我们要充 分关注基因组时代和干细胞时代的药物和医学技术开 发, 也要充分关注中医中药宝贵历史遗产的继承、弘扬 和现代化. 我国 13 亿或未来的 15 亿人口怎么能够享受 到公平、普惠的公共卫生和医疗保健, 这是构建和谐社 会提出的需要. 其中包含的许多科技问题世界上也没有 解决, 我们要从保障十几亿人口健康幸福出发, 从基础 研究做起, 并重视从实验室到产业和临床的转移转化研 究, 既要有前瞻思考, 又要牢记创新为民的宗旨. 基础 研究是有风险的, 定向应用和临床更需要经受市场和实 际的考验. 有些关于生命健康的重要基础问题, 和卓有 成效的健康科学系统知识创新和医药技术创新突破, 需 要长期不断的坚持研究创新才能解决.

\section{海洋科技要引起高度重视}

海洋在国家安全与权益、人类生存与可持续发展、 全球气候变化、食物资源及战略性能源与资源保持等方 面的重要地位, 已经引起世界各国的高度重视, 并成为 当代和未来经济与科技竞争的焦点之一. 我国是海洋大 国, 拥有 1.8 万公里海岸线, 近 300 万平方公里蓝色国 土, 蕴藏着丰富的海洋资源. 但是, 与欧美日等发达国 家相比, 我国的海洋产业和海洋科技还有较大的差距. 如何加强海洋科技的原始性创新、集成创新与前瞻部署, 认知海洋, 利用海洋, 实现海洋科技的跨越式发展, 满 足国家战略需求，成为国家和社会各界关注的重点. 在 海洋生物资源方面, 要深入研究海洋渔业资源、生物基 化学资源、微生物资源和生物基因资源, 实现海洋生物 技术和生物资源开发利用技术的创新与突破; 在海洋生 态系统与安全方面, 应全面提升近海生态系统和深海大 洋的观测与探测能力, 深化对海洋物理、化学、主要生 命现象与生态过程的认识, 提高对海洋自然与海洋灾害 的理解与预测能力, 为建立基于海洋生态系统活动规律 的海洋管理与开发模式, 保障海洋食品安全和清洁、健 康、稳定的海洋生态环境提供支撑; 在海洋油气与矿产 资源方面, 要利用创新的理论和先进的技术提高海洋油 气与矿产资源探测与资源评估能力, 深化对大陆架及海 洋油气形成、蕴藏与海底成矿的认识, 提高对海洋油气 与矿产资源的了解, 为海洋油气与矿产资源的勘探、开 发和利用提供关键科技支撑. 世界许多国家最近都出台 了海洋战略规划, 未来世界各国对海洋科技会愈加重视, 现在必须进行前瞻研究与部署, 在正在到来的新一轮海
洋竞争中争取主动地位.

\section{空间科技是国家重点的战略领域}

空间科技是当代科技、信息和国家安全的战略制高 点, 关系着保障国家安全、保护人类生存环境、实现人 与自然和谐发展以及提高人类生活质量、实现可持续发 展等重大问题. 中国作为一个大国, 也应该为人类探索 太空、深入了解宇宙的奥秘作出应有的贡献. 在空间科 学和宇宙学方面, 要前瞻部署研究黑洞、暗物质、暗能 量等科学问题和直接探测引力波, 研究太阳系的起源与 演化、太阳活动对地球环境的影响及其预报、地外生命 的探索等; 针对我国面临的能源、资源短缺和生态环境 问题, 应整合对地观测基础设施、构建数字地球科学平 台, 开展跨学科地球综合观测系统、模拟同化、协同反 演; 要结合我国航天发展战略, 利用先进的科技手段, 提高太空信息采集和处理能力, 加强空间生存与活动的 基础研究与应用开发, 研发新型的推进系统, 为深空探 测提供有力的支撑. 我国的经济和科技能力发展到今天, 空间科技不能只跟在一些国家的后面, 应树立新的科学 目标和发展战略, 服务经济社会发展和国家安全. 建设 创新型国家、提高国家的竞争能力要求我们在空间科技 领域要加强自主创新、原始创新, 加强整体性、战略性 的前瞻研究.

此外, 如何合理开发利用水资源、矿产资源、油气 资源, 如何合理高效可持续利用生物质资源, 如何解决 区域发展与国家经济社会发展中的瓶颈问题, 在这些关 系到我国经济社会发展重大问题中, 都蕴含着许多重大 的科技问题，需要我们科技界前瞻思考. 在信息、先进 制造、先进材料、纳米科技等与国家产业竞争力的提高 密切相关的问题中, 更是含有大量的科技难题需要我们 去攻克. 大科学工程、重大交叉学科的发展, 关系到我 国的基础研究能否取得突破性进展, 能否作出无愧时 代、无愧历史的贡献. 所有这些问题都需要我们见微知 著、未雨绸缪、早做部署.

我国实现社会主义现代化, 需要科学技术走在前 面, 需要科技人员想在前面. 我们要高度重视科学前瞻, 通过前瞻, 认识自身的不足; 通过前瞻, 认清形势和科 技发展的态势; 通过前瞻, 进一步凝炼创新目标. 我们 力争要在一些事关国家发展、安全和对经济社会发展具 有带动性的科技领域取得突破, 支持科学发展, 在若干 举世关注的重大科学问题破解上有所贡献, 把握未来科 技发展的主动权, 实现创新能力的提升与跨越, 迎接新 科技革命的挑战, 引领未来, 为我国现代化发展提供强 有力的支撑. 